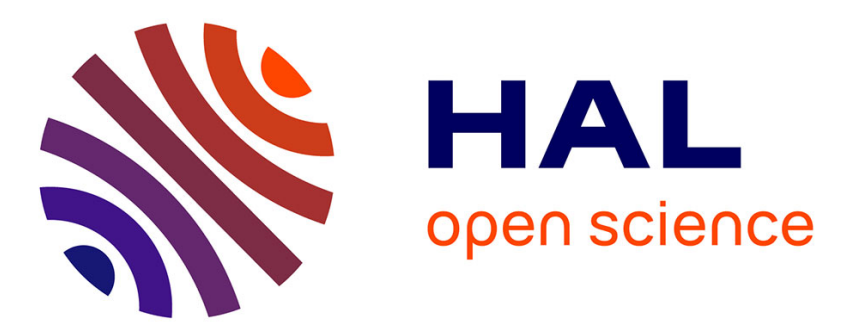

\title{
A Mesomechanical Modelling of Porous Aluminum under Dynamic Loading: Comparison Experiment-Calculation
}

\author{
Francis Collombet, S. Bonnan, P. Héreil
}

\section{- To cite this version:}

Francis Collombet, S. Bonnan, P. Héreil. A Mesomechanical Modelling of Porous Aluminum under Dynamic Loading: Comparison Experiment-Calculation. Journal de Physique IV Proceedings, 1997, 07 (C3), pp.C3-643-C3-648. 10.1051/jp4:19973110 . jpa-00255395

\section{HAL Id: jpa-00255395 https://hal.science/jpa-00255395}

Submitted on 1 Jan 1997

HAL is a multi-disciplinary open access archive for the deposit and dissemination of scientific research documents, whether they are published or not. The documents may come from teaching and research institutions in France or abroad, or from public or private research centers.
L'archive ouverte pluridisciplinaire HAL, est destinée au dépôt et à la diffusion de documents scientifiques de niveau recherche, publiés ou non, émanant des établissements d'enseignement et de recherche français ou étrangers, des laboratoires publics ou privés. 


\title{
A Mesomechanical Modelling of Porous Aluminum under Dynamic Loading: Comparison Experiment-Calculation
}

\author{
F. Collombet, S. Bonnan* and P.L. Héreil* \\ LAMEF - École Nationale Supérieure d'Arts et Métiers, Esplanade des Arts et Métiers, \\ 33405 Talence cedex, France \\ * Centre d'Études de Gramat, 46500 Gramat, France
}

\begin{abstract}
The purpose of this work is to demonstrate the validity of a model based on a method of homogenization (Mori and Tanaka's method) to study the shock-wave behavior of $8.2 \%$ porous aluminum. At low stresses (below $2 \mathrm{GPa}$ ), the macroscopic response of this material is influenced by the coupling between matrix plasticity and void collapse under stress triaxiality. The model is validated through the comparison of numerical simulations to an interferometric measurement performed during a plate impact test. For this approach, the satisfactory restoration of the experimental profile by the proposed model depends on the physical analysis of local events.
\end{abstract}

Résumé. Le but de ce travail est de prouver la validité d'un modèle basé sur une méthode d'homogénéisation pour l'étude du comportement sous onde de choc d'un aluminium poreux à $8.2 \%$ de porosité initiale. Même à bas niveau de contrainte, la triaxialité des contraintes influence la réponse mécanique macroscopique par le couplage entre la plasticité de la matrice et la compaction des pores. Le modèle est validé au travers de la comparaison entre simulations numériques et mesure par interférométrie au cours d'un essai d'impact de plaques. La bonne concordance entre les profils expérimental et numériques dépend de la qualité de l'analyse physique des événements locaux.

\section{INTRODUCTION}

The purpose of this paper is to present and validate a macroscopic model from the study of a $8.2 \%$ porous aluminum $\left(\rho=2.48 \mathrm{~g} / \mathrm{cm}^{3}\right)$ submitted to shock waves propagation in compression. The macroscopic behavior of these materials is influenced by the coupling existing between the void collapse and the plasticity induced in the matrix. The presence of pores modifies the local state of loading of the medium (concentration of stresses) and leads to matrix plasticity. On the mesomechanical scale, pores get closed under plasticity effect. During plate impact tests the stress state is triaxial. The role of the triaxiality of stresses had already been highlighted in the literature through the comparison of behavior of many porous metals subjected to hydrostatic and uniaxial strain loadings [1].

For low level of stresses $(<10 \mathrm{GPa}$ ), models of porous materials like $\mathrm{P}-\alpha$ model [2] where $\mathrm{P}$ is the mean stress and $\alpha$ the distention expressing the porosity, or hollow sphere model [3] only take into account the influence of the mean stress on void collapse. To take into account the influence of the shearing stresses, theoretical formulations [4] [5] of the yield law $F(\tau, P, \phi, Y)=0$ for a ductile porous material are proposed where $\tau$ is the second invariant of the stress deviator tensor, $P$ the mean stress, $\phi$ the porosity and $Y$ the current flow stress of the matrix. These theoretical analyses represent a porous material by means of the hollow sphere model that, due to its construction, neglects the interactions between voids and limits their morphology to sphere or cylinder.

The selected modeling is also based on the evolution of the yield function that as in the approach of Gurson [4], links the spherical and deviatoric parts of the macroscopic stress to porosity and plastic strain induced in the matrix. The chosen analytical [6] is derived from the extension of the homogenization method, known as Mori and Tanaka's method [7], to the case of a workhardening and isotropic elastoplastic matrix through the theory of secant moduli [8]. It allows to take into consideration the influence of the material intrinsic characteristics and of local physical mechanisms, on the macroscopic behavior of the material.

The main characteristics of porous aluminum are described in section 2 . Section 3 presents the mathematical analysis and the constitutive relations of the model. The last section concerns the comparisons between experimental measurement and simulations respectively issued from the proposed model and other approaches like P- $\alpha$ model and Gurson's formulation. 


\section{DESCRIPTION OF POROUS ALUMINUM}

Porous aluminum results from the sintering, in solid phase, of the powder of pure aluminum. This elaboration process allows to obtain a material which is macroscopically homogeneous and isotropic, and to control the initial rate of porosity.

Figure 1 is a photomicrograph of the mesoscopic structure. The conditions of elaboration do not allow, at the present time, to control pore morphology. The initial density of the studied porous aluminum is $2.48 \mathrm{~g} / \mathrm{cm}^{3}$ which corresponds to an initial porosity of $8.2 \%$. It can be defined apparently by bonded grains which size ranges from 10 to $120 \mu \mathrm{m}$. In the same way, the mesoscopic structure is characterized by voids randomly dispersed and oriented. However their shape is difficult to specify but it should be noted that their dimensions are lower than $10 \mu \mathrm{m}$.

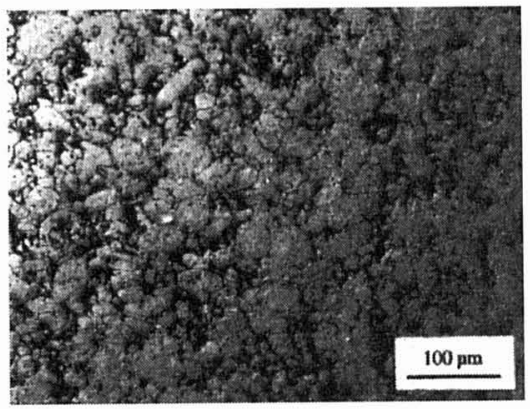

Figure 1 - Photomicrograph of the $8.2 \%$ porous aluminum

\section{THEORETICAL ANALYSIS}

As pore dimensions are small compared to shock front thickness $(>100 \mu \mathrm{m})$ in plate impacts [9], we choose a mathematical approach which neglects inertia effects on void collapse.

\subsection{Yield function of the porous material}

The yield function of the ductile porous material is deduced from the combination of Eshelby's Principle of Equivalent Inclusion [10], Mori and Tanaka's method [7], the secant moduli concept [8] and a criterion of matrix plasticity [11]. Finally, the expression is given by the following equation :

$$
F=4 \tau^{2}+\frac{3 \phi}{2} \frac{\left(2 \delta^{2}+1\right)}{\left(1-\phi+\phi a_{2}\right)\left(2 \delta^{2}-\left(\delta^{2}-1\right) g\right)} P^{2}-\frac{(1-\phi)^{2}}{\left(1-\phi+\phi a_{2}\right)} Y^{2}=0
$$

Relation (1) defines the condition of coupling between the mean stress $P$, the second invariant of macroscopic stresses $\tau$ equal to $\left(3 \Sigma_{\mathrm{ij}}^{\mathrm{d}} \Sigma_{\mathrm{ij}}^{\mathrm{d}} / 8\right)^{1 / 2}$ where $\Sigma_{\mathrm{ij}}^{\mathrm{d}}$ is the deviatoric stress, $\phi$ the porosity, $Y$ the yield limit representing the plasticity in the matrix, $\delta$ is the aspect ratio of spheroidal voids (length/diameter), $a_{2}$ and $g$ are parameters computed from components of Eshelby's tensor [11]. The Principle of Equivalent Inclusion takes into account the interaction between a spheroidal void and the surrounding elastic matrix. The interactions between voids are considered owing to Mori and Tanaka's method. The plastic behaviour of the matrix is introduced in Mori and Tanaka's method via the secant moduli technique. The criterion of matrix plasticity is defined from distortion energy to take into account the effects of the volume and deviatoric parts of the local stress tensor applied on mesoscopic scale. 
The limit $\mathrm{Y}$ is identified from quasistatic experiments performed through simple compression on dense aluminum at "Centre d'Etudes de Gramat". The eventual effects of strain and pressure rates on work hardening through dynamic loading are not involved in this mathematical law.

\subsection{Constitutive relations for the porous material}

The constitutive relations of the porous material are deduced from associated generalized plasticity laws where the yield function is identified as a plastic potential. The principle of maximal plastic work which is applied to the metal matrix (standard material), and then to the porous material [12], imposes to apply the normality law. The direction of plastic flow is consequently fixed. So, the unknown quantities are macroscopic stress, macroscopic plastic strain, porosity, and plastic strain induced in the matrix. The aspect ratio $\delta$ is supposed to remain constant during shock wave loading.

The macroscopic plastic strain rate $\dot{\mathrm{E}}_{\mathrm{ij}}^{\mathrm{p}}$ is deduced from the normality rule :

$$
\dot{\mathrm{E}}_{\mathrm{ij}}^{\mathrm{p}}=\frac{\partial \mathrm{F}}{\partial \Sigma_{\mathrm{ij}}} \dot{\lambda}
$$

where $\Sigma_{\mathrm{ij}}$ is macroscopic stress and $\dot{\lambda}$ a positive scalar. With (2) the hypothesis of matrix incompressibility relates the porosity variation (void collapse) to the plastic volume strain of the porous material :

$$
\dot{\phi}=-(1-\phi) \frac{\partial \mathrm{F}}{\partial \mathrm{P}} \dot{\lambda}
$$

In the same manner, the deviatoric plastic strain rate $\dot{\mathrm{e}}_{\mathrm{ij}}^{\mathrm{p}}$ via the second invariant $\dot{\gamma}=\left(3 \dot{\mathrm{e}}_{\mathrm{ij}}^{\mathrm{p}} \dot{\mathrm{e}}_{\mathrm{ij}}^{\mathrm{p}} / 8\right)^{1 / 2}$ is deduced from (2) :

$$
\dot{\gamma}=\frac{1}{2} \frac{\partial \mathrm{F}}{\partial \tau} \dot{\lambda}
$$

Macroscopic mean and deviatoric stresses are linked to elastic strains [13] :

$$
\begin{aligned}
& \dot{\mathrm{P}}=-(1-\phi) \mathrm{k}_{\mathrm{m}} \dot{\mathrm{E}}_{\mathrm{kk}}-\left[\frac{2+\Gamma_{\mathrm{m}}}{1-\phi} \mathrm{P}-\mathrm{k}_{\mathrm{m}}\right] \dot{\phi}+2 \Gamma_{\mathrm{m}} \tau \dot{\gamma} \\
& \frac{2}{\mu} \dot{\tau}+3 \dot{\gamma}=3 \dot{\varepsilon}-\dot{\mathrm{E}}_{\mathrm{kk}}
\end{aligned}
$$

where $\mathrm{k}_{\mathrm{m}}$ and $\Gamma_{\mathrm{m}}$ are the bulk modulus and the Mie-Grüneisen factor of the matrix, $\mu$ the porous material shear modulus calculated from Mori and Tanaka's method [14], $\dot{\mathrm{E}}_{\mathrm{kk}}$ the total volume strain rate and $\dot{\varepsilon}$ the macroscopic strain rate applied (in uniaxial strain : $\dot{\varepsilon}=\dot{\mathrm{E}}_{\mathrm{kk}}$ ).

The plastic strain in the matrix is on the contrary determined with a phenomenological and macroscopic identification of the plastic dissipation generated in the porous material. The relation to the matrix local plasticity is obtained with the average criterion of Gurson [4]. For that, the macroscopic plastic dissipation $\Sigma_{\mathrm{ij}} \dot{\mathrm{E}}_{\mathrm{ij}}^{\mathrm{p}}$ is associated to the dissipation of a medium presenting identical porosity and homogeneously work hardened with the plastic strain increment $\dot{\gamma}_{\mathrm{m}}$ :

$$
-\frac{\mathrm{P}}{(1-\phi)} \dot{\phi}+2 \tau \dot{\gamma}=(1-\phi) \mathrm{Y} \dot{\gamma}_{\mathrm{m}}
$$


The condition of consistency is the necessary and sufficient condition so that the representative point $\left(\mathrm{P}, \tau, \phi, \gamma, \gamma_{\mathrm{m}}\right)$ of the material macroscopic state remains on the yield function during plastic flow :

$$
\dot{\mathrm{F}}=\mathrm{F}_{\tau} \dot{\tau}+\mathrm{F}_{\mathrm{p}} \dot{\mathrm{P}}+\mathrm{F}_{\phi} \dot{\phi}+\mathrm{F}_{\gamma_{\mathrm{m}}} \dot{\gamma}_{\mathrm{m}}=0
$$

The positive scalar $\dot{\lambda}$ is calculated from relation (8). A differential system of type $A y^{\prime}=x$ is deduced from the equations (3), (4), (5), (6) and (7) whose unknown quantities are $\dot{\tau}, \dot{\mathbf{P}}, \dot{\gamma}, \dot{\gamma}_{\mathrm{m}}$ and $\dot{\phi}$. This system is resolved through a Runge-Kutta scheme with, for calculation step, the time step dt imposed by the unidimensional Lagrangian finite difference code UNIDIM issued from WONDY [15].

\section{COMPARISONS BETWEEN EXPERIMENTAL MEASUREMENT AND SIMULATION}

Principle of the selected experimental configuration is presented on Figure 2 and discussed in [9]. The projectile made of a PMMA specimen and an Al6061-T6 specimen, impacts a target containing $8.2 \%$ porous aluminum.

$(9,98 \mathrm{~mm}) \quad(10,94 \mathrm{~mm})$

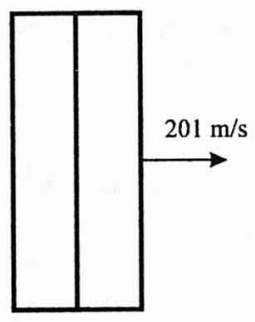

$\mathrm{Al} 6061$ Porous Aluminum $(2,00 \mathrm{~mm})(5,03 \mathrm{~mm})$

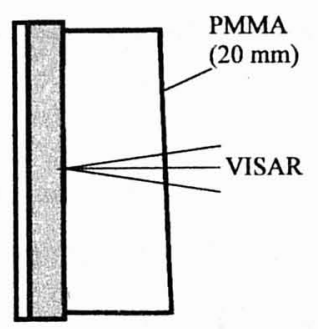

Figure 2 - Plate impact test configuration.

In Figure 3 the VISAR velocity profile of the porous aluminum-PMMA interface is presented. These dynamic measurements can be associated to physical mechanisms through Lagrangian analysis [16]. The five steps numbered from (1) to (5) on Figure 3 result from the following phenomena. Phase (1) corresponding to the first wave, is associated to the effect of the elastic precursor : the behavior of porous aluminum is supposed to remain in the elastic domain without void collapse. Phase (2) corresponds to a continuous transition between the elastic precursor and the collapse wave, and results in a consolidation effect (work-hardening) of the material beyond its elastic limit. Phase (3) expresses the propagation of the second collapse wave whose rising time is evaluated to about $80 \mathrm{~ns}$. During its propagation, voids get closed due to the plasticity induced in the matrix. Phase (4) is associated to a plateau of maximal velocity which corresponds to a stabilized 
state of the material. Phase (5) corresponds to a release wave issued from the reflection of the compression wave in the impactor at the interface between A16061-T6 and PMMA.

For every calculation presented in this paper, the numerical mesh thickness in porous aluminum is equal to $50 \mu \mathrm{m}$. This length is supposed to be sufficiently large to represent the homogeneous equivalent material compared to average void dimensions. Moreover, values of pseudo-viscosity coefficients are minimum to stabilize the numerical scheme.

As shown on Figure 4, a good agreement between experimentation and calculation, obtained for the interface velocity profile, is established for the aspect ratio $\delta=0.3$. The advent times of the elastic precursor and collapse wave, as well as the progressive rising of the interface velocity profile due to work hardening, are accurately computed for this $\delta$ value. Of course, this aspect ratio value is not a quantitative geometrical reference as shown in Figure 1, but a qualitative one to represent the void morphology of porous aluminum.

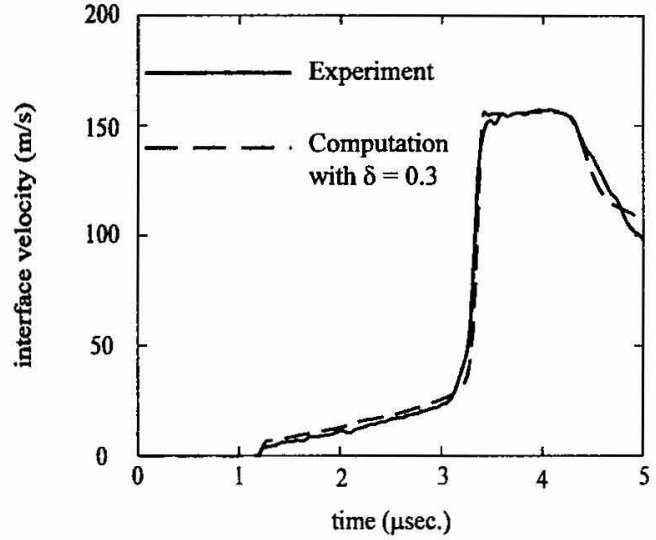

Figure 4 - Comparison experimentation-calculation with the proposed model.

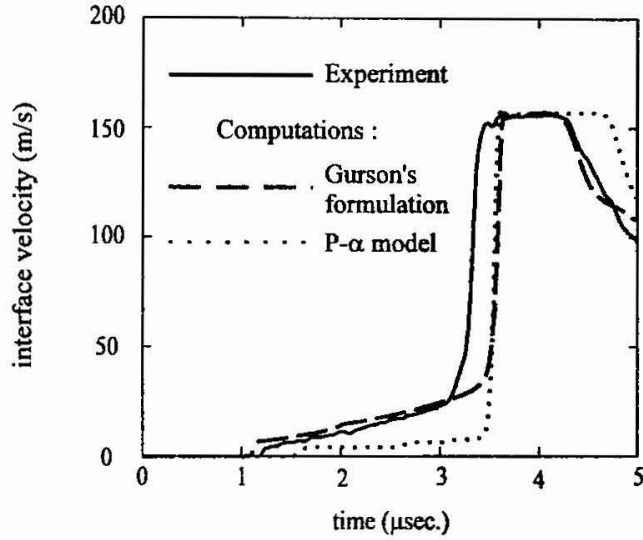

Figure 5 : Comparisons between experimentation and calculations for the Gurson's and P- $\alpha$ models.

The implemented experimental configuration does not emphasize the presence of dynamic effects, notably in the rising time value of the collapse wave. Numerical results reproduce this rising time although the model is developed on a quasistatic approach.

To demonstrate the validity and consistency of the chosen modeling, comparisons were performed between experimentation and calculations issued from other behavior models like P- $\alpha$ model [2] and the yield function proposed by Gurson [4]. Comparisons are presented on Figure 5. The numerical values obtained with these models for the advent time of the elastic precursor, rising of velocity profile due to work hardening, and the advent time of the collapse wave present distinctly a lower agreement with experimentation results. Those differences may appear because interactions between voids are neglected and pore morphology is limited to sphere. Figure 5 also shows one of the limitation of P- $\alpha$ type models that doesn't restore the rising of velocity profile due to work hardening in the matrix. 


\section{CONCLUSION}

Modeling choices in representing the shock wave behavior (plate impact) of a porous aluminum through a physical analysis that involves the preponderant parameters or events, constitutes a progress in relation to models existing in the literature. Owing to the reliability of VISAR measurements, the proposed approach is confirmed to be appropriate to reproduce experimental profiles in the case of unidimensional wave. This agreement accounts for the preponderant influence of the coupling between void collapse and plasticity induced in the matrix, the stress triaxiality and void morphology on the dynamic behavior of porous aluminum.

It should be noted that, in the proposed experimental configuration, dynamic effects if any (i.e. inertia effects or viscoplasticity in the matrix) do not seem to be of first order influence if we refer to the present comparison between calculation and experimentation. This work can also be extended to any type of porous material after identification of the work hardening elastoplastic behavior of the matrix.

\section{REFERENCES}

[1] Johnson J. N. et al., 1974, in "The Influence of Deviatoric Stress in the Compaction of Porous Metals at High Pressure", Proc. of the Fourth Int. Conf. on High Pressure, pp. 130-137, Phys.-Chem. Soc. of Japan, Kyoto, Japan.

[2] Herrmann W., 1969, J. Appl. Phys., Vol. 40, p. 2490.

[3] Carroll M. M., Holt A. C., 1972, J. Appl. Phys., Vol 43, 1626.

[4] Gurson A. L., 1977, "Continuum Theory of Ductile Rupture by Void Nucleation and Growth : Part I- Yield Criteria and Flow Rules for Porous Ductile Media", ASME J. Eng. Mat. Tech., Trans. ASME, 99, 2.

[5] Tvergaard V., 1981, International J. of Fracture, Vol. 17, pp. 389-407.

[6] Qiu Y. P. and Weng G. J., 1993, Int. J. of Plasticity, Vol. 9, pp. 271-290.

[7] Mori T. and Tanaka K., 1973, Acta Metallurgica, Vol. 21, pp.571-574.

[8] Berveiller M. and Zaoui A., 1979, J. of the Mechanics and Physics of Solids, Vol. 26, p. 325.

[9] Héreil P. L., Bonnan S. and Collombet F., 1997, "Experimental Characterization of Shock Wave Behavior of Porous Aluminum", EURODYMAT 97, Toledo, Spain.

[10] Eshelby J. D., 1961, "Elastic Inclusions and Inhomogeneities", Progress in Solid Mechanics, Chapter 3, pp 87-140.

[11] Qiu Y. P. and Weng G. J., 1992, ASME Journal of Applied Mechanics, Vol. 59, pp. 261-268.

[12] Mear M. E., 1986, "The Plastic Yielding of Porous Metals", PH. D. Th. of Harv. University.

[13] Johnson J. N. and Adessio F. L., 1988, J. Appl. Phys., 64(12), pp. 6699-6712.

[14] Tandon G. P. and Weng G. J., 1986, "Average Stress in the Matrix and Effective Moduli of Randomly Oriented Composites", Composite Science and Technology, Vol. 27, pp. 111-132.

[15] Kipp M. E. and Lawrence R. J., 1982, "WONDY V : A One-Dimensional Finite-Difference Wave-Propagation Code", Report SAND81-0930, Sandia National Laboratories, New Mexico.

[16] Seaman L., 1974, J. Appl. Phys., Vol. 45, No. 10, 4303. 